\title{
Fuzzy Based Adaptive Two Phase Traffic Signal Controller
}

\author{
${ }^{* 1}$ Prof. Gajanan Babhulkar, ${ }^{2}$ Prof. Payal Jadhav, ${ }^{3}$ Prof. Bhumesh Masram, ${ }^{4}$ Prof. Prachiti Pimple, ${ }^{5}$ Prof. \\ Priya Maidamwar \\ ${ }^{1}$ Dr. D. Y. Patil College of Engineering, Pune, \\ ${ }^{2}$ PES Modern College of Engineering, Pune, \\ ${ }^{3}$ PICT, Pune, \\ ${ }^{4}$ K.K. Wagh Institute of Engineering Education and Research, Nashik, \\ ${ }^{5} \mathrm{G} H$ Raisoni College of Engineering Nagpur \\ *Email: babhulkarg@gmail.com
}

Received: 09 ${ }^{\text {th }}$ July 2018, Accepted: $14^{\text {th }}$ August 2018, Published: $31^{\text {st }}$ August 2018

\begin{abstract}
An adaptive traffic signal controller computes the phase timings based on real-time data of traffic and it generally results in better performance for various traffic situations. In general the fuzzy traffic signal controllers are proved to be better as compared to the traditional fixed-time controller. However the decisions were made on traffic conditions and the significance of phase sequence was suppressed. This research work dealt with the new fuzzy traffic signal controller for a full single intersection. The proposed fuzzy controller includes two main phases: fuzzy phase selection mechanism and fuzzy green time decision. The first phase will decides the next phase to be green and second phase decides the green timings for the corresponding phase. The proposed fully approach is compared with the traditional fixed-timed control system (FTC) and experimental results shows the significance reduction in average waiting time at the intersection and average queue length over fixedtimed control.
\end{abstract}

Keywords: Traffic Signal Controller, Adaptive Traffic Signal, Fuzzy Traffic Signal Controller.

\section{Introduction}

Traditionally the traffic signal controller systems are implemented using the fixed-timed controller, wherein the green and red phases timings are constant throughout signal phase cycle. The implementation of fixed-timed controller is easy but it results in poor performance for medium to heavy traffic situations. An adaptive traffic signal controller computes the phase timings based on real-time data of traffic and it generally results in better performance for various traffic situations. Uncertainty and randomness are the usual characteristics of traffic flow, hence adaptive traffic signal controller instead of fixed-time controller will be sensible alternative. Zadeh in 1965 introduced the concept of fuzzy logic and since then fuzzy logic has been extensively used to solve several engineering problems and it is best suited for control and modelling
(Zadeh 1965). Application of fuzzy logic in traffic engineering is provided by (Rahman and Ratrout 2009) wherein a fuzzy logic based traffic signal controller is proposed for Saudi Arabia. (Pappis and Mamdani 1977) proposed a model for two way traffic junction (each way of single lane) which will terminate the current green phase based vehicle count measured by inductive loop detectors. Same configuration was adopted by (Bingham 2001) wherein the parameters of fuzzy traffic controller are determined by the reinforcement learning algorithm. A transportation and traffic processes is modelled using fuzzy logic (Teodorovic 1999) and inference was fuzzy logic and fuzzy set theory presents a mathematical mechanism to model complex transportation and traffic processes. A fuzzy traffic control system for two-way junction is proposed (Zarandi and Othman 2011) wherein the traffic signal timings were adjusted based on current level of traffic situation. The proposed model was tested for state of Kuwait and it results in reducing vehicle delay at an intersection. A fuzzy logic traffic controller for an isolated intersection (Trabia et. al., 1999) was proposed wherein the controller is responding to the real-time traffic demands and it results in lower waiting time at intersection.

A monitoring technologies based adaptive traffic light controller is proposed by (Wong and Woon 2008) wherein a fuzzy logic based mechanisms is used to represent the prototype of the prediction module. A two stage fuzzy logic based traffic control model for an isolated unction was proposed (Jian et. al., 2011), wherein the traffic fairness and efficiency were considered simultaneously. A neuro-fuzzy system which is also called as Pseudo Outer-Product FuzzyNeural Network using Truth-Value-Restriction method (POPFNN-TVR) was proposed (Quek et. al., 2009), for modelling the traffic behaviour. A traffic signal control system based on multi-agent control mechanism, real-time simulation and fuzzy inference method was proposed (Kosonen 2003), wherein every signal act as an individual agent and negotiates with 
the other signals about control strategy and the decision making was based on fuzzy inference which allows the combinations of several aspects like safety, economy, fluency and environment. A fuzzy signal controller for an incomplete intersection with twoway lanes and left-turn ways was proposed (Zarandi and Rezapour 2009), wherein real time information of traffic and fuzzy rules were used to take the decision. A hybrid model was proposed by (Barzegar et. al., 2011), which based on combination of fuzzy logic, Petri nets and the learning automata. The system results in significant reduction in waiting time at intersection.

In general the fuzzy traffic signal controllers are proved to be better as compared to the traditional fixed-time controller. However the decisions were made on traffic conditions and the significance of phase sequence was suppressed. The proposed fuzzy controller includes two main phases: fuzzy phase selection mechanism and fuzzy green time decision. The first phase will decides the next phase to be green and second phase decides the green timings for the corresponding phase.

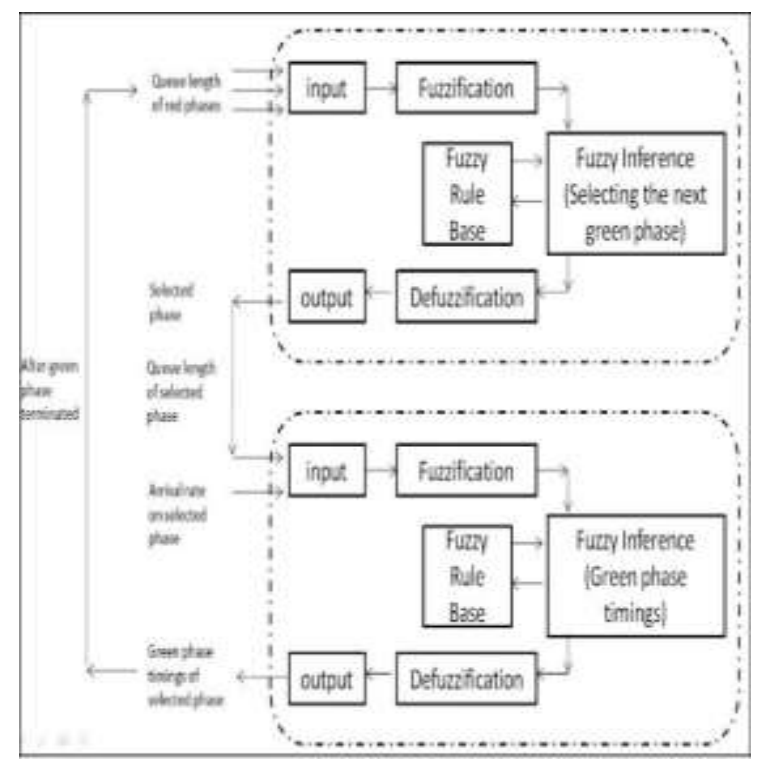

Figure 1. Architecture of an Adaptive Traffic Signal Controller

Fuzzy phase selector: In order to get the best phase sequence, the fuzzy phase selector decides the next phase to be green based on queue length of all red phases at intersection. Figure 2 shows the typical intersection phases and geometry considered for this study. Figure 3 shows the phases of an intersection

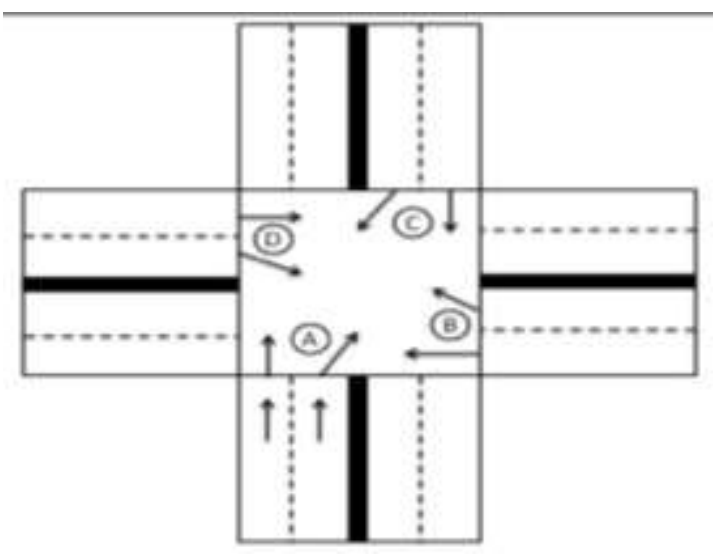

Fig 2: Intersection Phases and Geometry

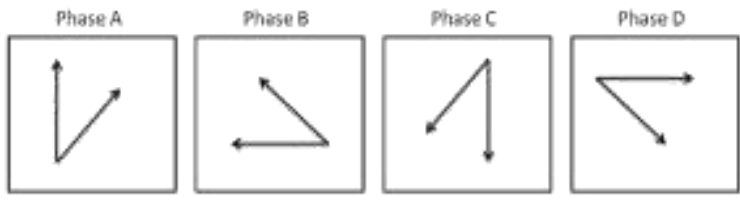

Figure 3. Phases of Traffic Signal Controller

The queue length of red phases is input to the fuzzy controller and next phase to be green is decided as output. For example, at any instance of time ${ }_{1}$, if the phase $\mathrm{A}$ of an intersection is going to be terminated then next phase is to be selected is either B or C or D. The queue length of phase $\mathrm{B}, \mathrm{C}$ and $\mathrm{D}$ are input to the fuzzy controller and next phase that will be green is output. The fuzzy membership functions of queue length is as follows,

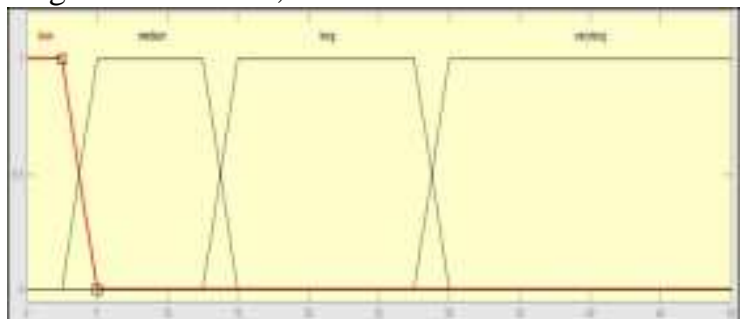

Figure 4. Fuzzy Membership Functions for Queue Length

A total 64 rules were formulated and it is illustrated as follows,

If ( $Q R B$ is low) and ( $Q R C$ is low) and $(Q R D$ is low) then (B is green)(C is red)( $D$ is red) (1)

Rule 1 indicates one of the rule, if the queue length of phase $B$ is low and queue length of phase $C$ is low and queue length of phase $\mathrm{D}$ is low then phase $\mathrm{B}$ will be green and phase $\mathrm{C} \& \mathrm{D}$ will be red.

Green timing decision: The queue length of the selected phase and arrival rate of vehicles are now considered as input to the fuzzy green time computation phase and adaptive traffic signal green timings will be the output. The fuzzy membership 
function of vehicle arrival rate (vehicle/min) and green phase timings are as follows,

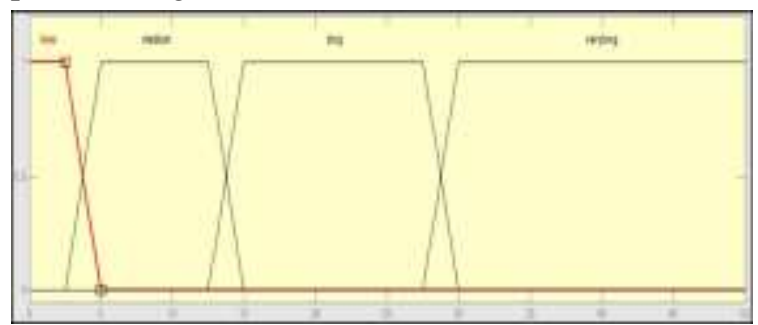

Figure 5. Fuzzy Membership Functions for Vehicle Arrival Rate

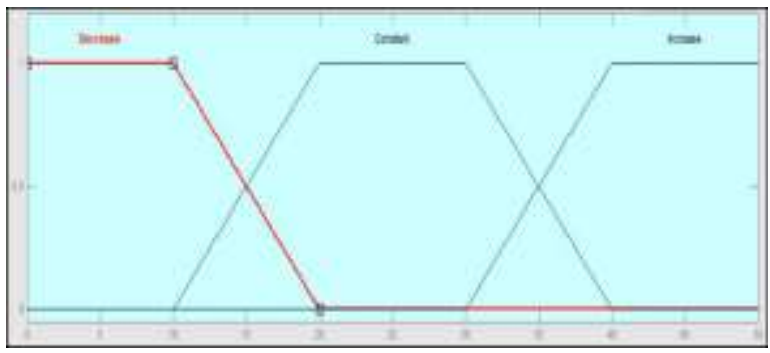

Figure 6. Fuzzy Membership Functions for Green Phase Timings

Overall 20 rules were framed for the green phase timings and one of the rules is as follows,

If (Queue is low)and (Arrival is Verysmall)

then (output1 is Decrease) (2)

It indicates that if queue length is low and arrival rate of vehicles is very small then green phase timings will be less or decreased.

\section{Experimental Results}

Study area: An area segment of Nagpur city from Hingna T-point to Variety Square is considered for this study. The considered area segment is shown in figure 7, Total 31 signalized intersections were considered and about 40 links were analyzed. To manage the overall study of above area segment only signalized intersections were considered.

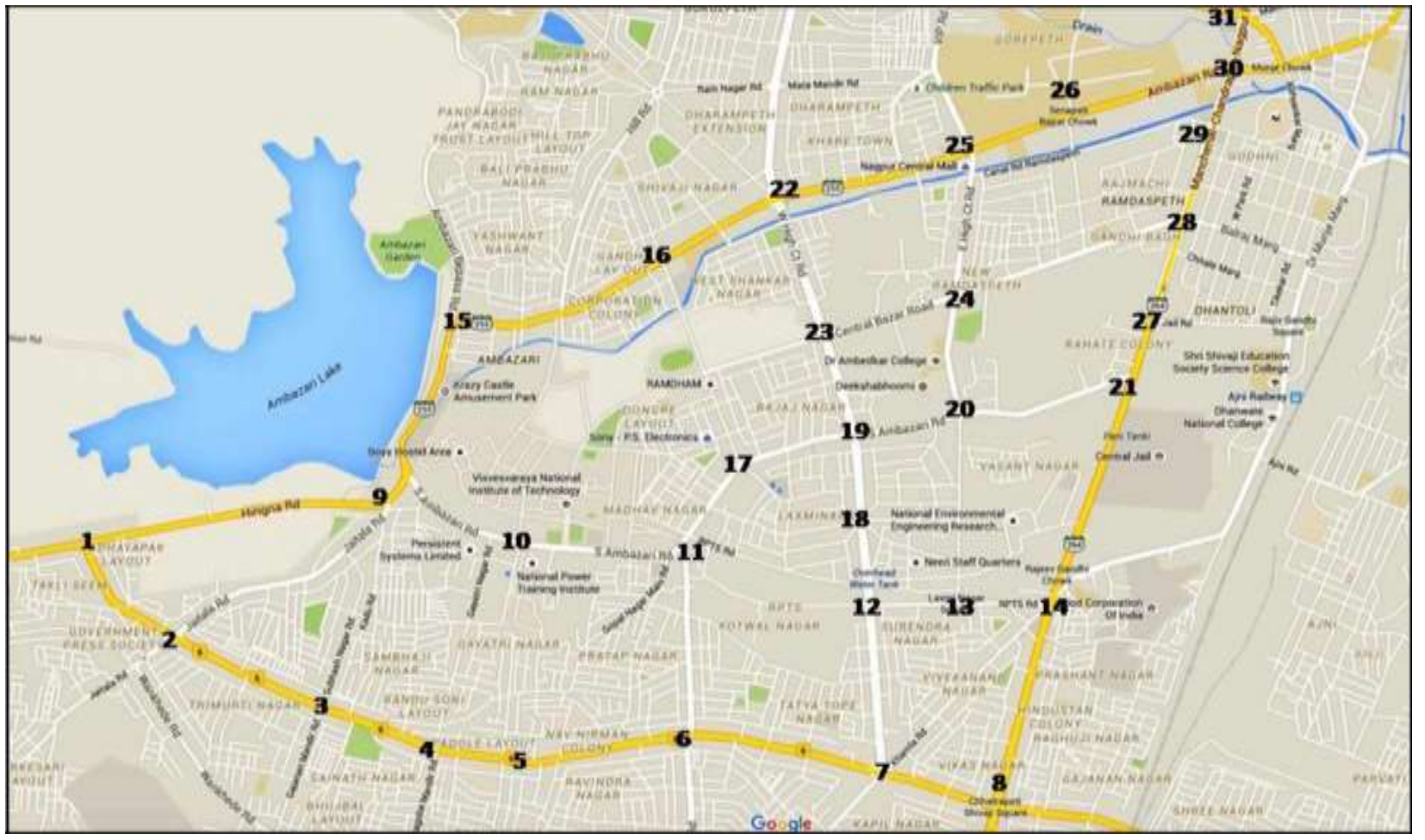

Figure 7. Area Segment of Nagpur City (From Hingna T-Point to Variety Square) for Study

The performance of proposed fuzzy logic traffic signal controller is compared with the traditional fixed-timed controller under two criteria namely the average waiting time of vehicles and average queue length. Experiments have been carried out for varying traffic volumes such as 0 to 300,300 to 900,900 to 1800 ,
1800 to 2700,2700 to 3600,3600 to 4800,4800 to 6000 and 6000 to 7200 . Table I shows the performance of proposed fuzzy controller over fixed-timed controller. From the experiments it is observed that, the average queue length using fuzzy controller is reduced by 65 to $70 \%$ and average waiting time is 
Helix Vol. 8(5): 4010- 4013

reduced to 66 to $69 \%$ as compared to fixed-timed controller.

\begin{tabular}{|l|l|l|l|l|}
\hline $\begin{array}{l}\text { Arrival } \\
\text { rate } \\
\text { (Veh/h) }\end{array}$ & $\begin{array}{l}\text { Average } \\
\text { queue } \\
\text { length by } \\
\text { fixed } \\
\text { time } \\
\text { controller }\end{array}$ & $\begin{array}{l}\text { Average } \\
\text { queue } \\
\text { length by } \\
\text { fuzzy } \\
\text { controller } \\
\text { waiting } \\
\text { time by } \\
\text { fixed } \\
\text { time } \\
\text { controller } \\
\text { (sec/veh) }\end{array}$ & $\begin{array}{l}\text { Average } \\
\text { waiting } \\
\text { time by } \\
\text { fuzzy } \\
\text { controller } \\
\text { (sec/veh) }\end{array}$ \\
\hline $\begin{array}{l}0 \text { to } \\
300\end{array}$ & 0.723 & 0.241 & 34.56 & 11.48 \\
\hline $\begin{array}{l}300 \text { to } \\
900\end{array}$ & 2.88 & 0.93 & 42.37 & 14.07 \\
\hline $\begin{array}{l}900 \text { to } \\
1800\end{array}$ & 5.82 & 1.89 & 51.05 & 16.31 \\
\hline $\begin{array}{l}1800 \text { to } \\
2700\end{array}$ & 10.03 & 3.13 & 56.2 & 18.67 \\
\hline $\begin{array}{l}2700 \text { to } \\
3600\end{array}$ & 13.84 & 4.11 & 58.22 & 19.34 \\
\hline $\begin{array}{l}3600 \text { to } \\
4800\end{array}$ & 18.45 & 5.59 & 61.11 & 20.3 \\
\hline $\begin{array}{l}4800 \text { to } \\
6000\end{array}$ & 24.69 & 7.27 & 63.37 & 21.05 \\
\hline $\begin{array}{l}6000 \text { to } \\
7200\end{array}$ & 29.68 & 9.27 & 67.55 & 22.29 \\
\hline
\end{tabular}

Table I. Experimental Results for Various Traffic Volumes

\section{Conclusion}

An adaptive traffic signal controller computes the phase timings based on real-time data of traffic and it generally results in better performance for various traffic situations. In this research work a new fuzzy traffic signal controller for a full single intersection is proposed. The proposed fuzzy controller includes two main phases: fuzzy phase selection mechanism and fuzzy green time decision. The first phase will decides the next phase to be green and second phase decides the green timings for the corresponding phase. The proposed fully approach is compared with the traditional fixed-timed control system (FTC) and experimental results shows the significance reduction in average waiting time at the intersection and average queue length over fixedtimed control.

\section{References}

1. Barzegar S, Davoudpour M, Meybodi M, Sadeghian M. and Tirandazian M. 2011.Formalized learning automata with adaptive fuzzy coloured Petri net; an application specific to managing traffic signals. Scientia Iranica, Volume 18, no. 3, pp. 554-565.

2. Bingham E. 2001. Reinforcement learning in neuro fuzzy traffic signal control. European Journal of Operational Research, Volume 131, no. 2, pp. 232-241.
3. Jian Q, Naiding Y and Jie G. 2011. Two-stage fuzzy logic controller for signalized intersection. IEEE Transactions on Systems, Man and Cybernetics, Part A: Systems and Humans, Volume 41, no. 1, pp. 178-184.

4. Kosonen L. 2003. Multi-agent fuzzy signal control based on real-time simulation. Transportation Research Part C, Volume 11, no. 5, pp. 389-403.

5. Pappis C. P. and Mamdani E. H. 1977. A fuzzy logic controller for a traffic junction. IEEE Transactions on Systems, Man and Cybernetics, Volume 7, no. 10, pp. 707-717.

6. Quek C, Pasquier M. and Lim B. 2009. A novel self-organizing fuzzy rule-based for modelling traffic flow behaviour. Expert Systems with Applications, Volume 36, no. 10, pp. 1216712178.

7. Rahman S. and Ratrout N. 2009. Review of fuzzy logic based approach in traffic signal control: prospects in Saudi Arabis. Journal of Transportation Systems Engineering and Information Technology, Volume 9, no. 5, pp. 5870.

8. Teodorovic D. 1999. Fuzzy logic systems for transportation engineering: the state of the art. Transportation Research Part A, Volume 33, no. 5, pp. 337-364.

9. Trabia M, Kaseko M and Ande M. 1999. A twostage fuzzy logic controller for traffic signals. Transportation Research Part C, Volume 7, no. 6, pp. 353-367.

10. Wong Y and Woon W. 2008. An iterative Approach to enhanced traffic signal optimization. Expert Systems with Applications, Volume 34, no. 4, pp. 2885-2890.

11. Zadeh L. 1965. Fuzzy sets. Information and Control, Volume 8, no. 3, pp. 338-353.

12. Zarandi M. and Rezapour S. 2009. A fuzzy signal controller for isolated intersections. Journal of Uncertain Systems, Volume 3, no. 3, pp. 174-182.

13. Zarandi M. and Al Othman W. 2011. Development of a fuzzy logic traffic system for isolated signalized intersection in the State of Kuwait. Expert Systems with Applications, Volume 38, no. 8, pp. 9434-9441. 